\title{
THE ENZYMATIC CHARACTERISTICS OF PEROXISOMES OF AMPHIBIAN AND AVIAN LIVER AND KIDNEY
}

\author{
Patricia J. Scott*, Louis P. Visentin $\dagger$, and John M. Allen, Ph.D. \\ Department of Zoology, The University of Michigan \\ Ann Arbor, Mich.
}

Peroxisomes have been identified on the basis of morphological criteria in a variety of species (Hruban and Rechcigl, 1969). Biochemical characterization, however, has been limited to rat liver (deDuve \& Baudhuin, 1966; Leighton, et al., 1968), rat kidney (Allen et al., 1965; deDuve \& Baudhuin, 1966), Tetrahymena pyriformis (Baudhuin et al., 1965b; Müller et al., 1968), Acanthoamoeba (Müller and Møller, 1967), germinating castor beans (Breidenbach et al., 1968), and the leaves of several plants (Tolbert et al., 1968a; Tolbert et al., $1968 \mathrm{~b})$. In germinating castor beans the peroxisome contains the enzymes of the glyoxylate cycle and, thus, may function in glyconeogenesis (Breidenbach et al., 1968). The peroxisome in leaf tissue contains glycolate oxidase and NADH-glyoxylate reductase and may function in photorespiration (Tolbert et al., 1968a; Tolbert et al., 1968b). In Tetrahymena, remnants of the glyoxylate cycle are present (isocitrate lyase and malate synthetase) (Müller et al., 1968), while in higher animals the components of the cycle appear to be absent. In these latter groups, the peroxisome appears to be limited in its enzymatic composition to catalase, D-amino acid oxidase, $\alpha$-hydroxy acid oxidase, and urate oxidase (in rat liver but not in rat kidney) (deDuve \& Baudhuin, 1966). In these cases it is difficult to define any unified metabolic role for peroxisomes, although it has been suggested that they may participate in coupled peroxidatic reactions, or in the regeneration of nicotinamide adenine dinucleotide (NAD) from reduced NAD, or in the production of keto-acids that may be utilized in fatty acid synthesis (deDuve \& Baudhuin, 1966).

Our attention has been directed toward the possible significance of urate oxidase in the peroxisomes of some species. This enzyme is a participant in the sequence of enzymes responsible for the degradation of purines. This sequence, in its complete form (FIGURE 1), leads to the formation of glyoxylate and urea, the latter ultimately being hydrolyzed to carbon dioxide and ammonia in certain groups (Brown et al., 1966). It has been suggested that the glyoxylate formed through the action of this sequence may be aminated and subsequently incorporated into purine, thus constituting a purine cycle (Brown et al., 1966). The extent to which this cycle generally exists is unknown.

The purine catabolic sequence is of further interest in that it has been subject to considerable evolutionary modification (FIGURE 1) (Baldwin, 1964) and might be expected to furnish clues to the evolution of a particle containing its components. We have undertaken a preliminary survey of the association of

\footnotetext{
- Recipient of a National Institutes of Health Training Grant Fellowship administered by the Department of Zoology, The University of Michigan (NIH ST01 6M 989). Portions of this work dealing with avian peroxisomes will be offered in partial fulfillment of the requirements for the Ph.D. degree, The University of Michigan.

† Recipjent of a Graduate Training Fellowship administered by the National Research Council of Canada (1560). Portions of this work dealing with amphibian peroxisomes will be offered in partial fulfillment of the requirements for the Ph.D. degree, The University of Michigan.
} 

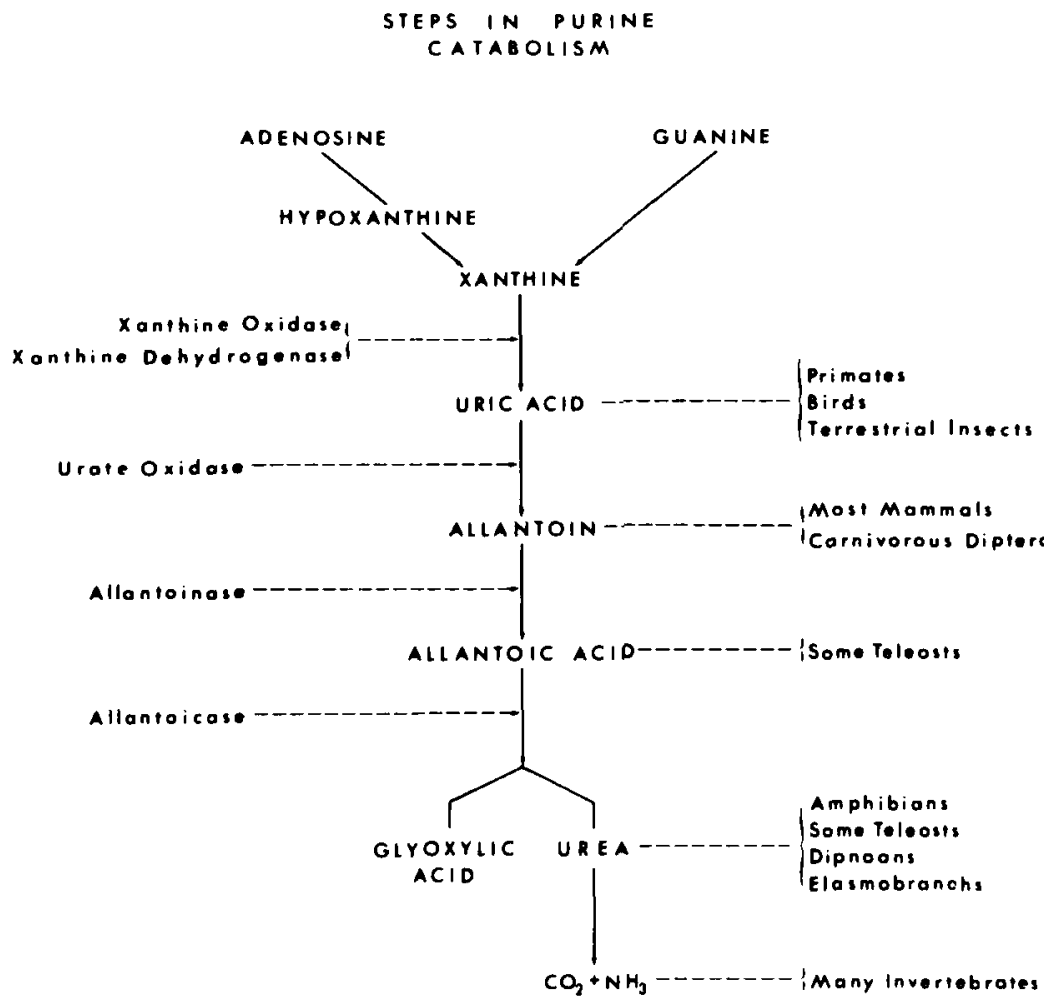

FIGURE 1. General aspects of purine catabolism. The intermediate steps of purine catabolism are shown in the central column, the enzymes responsible for the breakdown of various intermediates are shown in the left column, and the various animal groups utilizing particular intermediates as their primary excretory product of purine catabolism are shown in the right column.

elements of this sequence with peroxisomes derived from several animal species. The present paper reports the results of our investigations utilizing the liver and kidney tissue of Gallus gallus and Rana pipiens. In these tissues we have been able to identify peroxisomes by electron microscopy and by centrifugation methods utilizing the standard biochemical markers for these particles (catalase, D-amino acid oxidase, $\alpha$-hydroxy acid oxidase, and urate oxidase). In addition, we have established the association of xanthine dehydrogenase with the peroxisomes of chicken liver, and kidney and allantoinase with the peroxisomes of frog liver (Visentin \& Allen, 1969).

\section{Materials and Methods}

\section{Animals}

Adult Rana pipiens were obtained from the Lemberger Company, Oshkosh, Wisconsin. Animals were housed in an aquarium tank, the bottom of which was covered by a moist layer of sand, and they were fed daily with either flesh flies or bits of fresh liver. The temperature of the aquarium facility was maintained at 
approximately $20^{\circ} \mathrm{C}$. Day length was not regulated. Animals were starved for 24 hours prior to sacrifice.

White leghorn pullets, DeKalb strain 151, between the ages of 13 and 24 weeks were obtained from the Klager Hatchery, Bridgewater, Michigan. These animals were maintained on a constant day length of 17 hours at a temperature of approximately $20^{\circ} \mathrm{C}$. They were fed a $14 \%$ protein mash (Washtenaw Farm and Garden Center, Ann Arbor, Michigan) and water ad libitum. Animals were starved for 15 hours prior to sacrifice.

\section{Tissue Homogenates}

Homogenization in all cases was accomplished by three up-down strokes of a loose fitting Teflon pestle rotated at $120 \mathrm{rpm}$ in a smooth glass homogenizer. During all preparative procedures tissue samples were maintained near $0^{\circ} \mathrm{C}$. Animals were routinely sacrificed between 8:00 AM and 10.00 AM.

\section{Rana}

Pooled samples of liver or kidney derived from three animals were scissor minced and $10 \%(\mathrm{w} / \mathrm{v})$ homogenates were prepared in $0.25 \mathrm{M}$ sucrose (Mallinckrodt) containing $0.01 \mathrm{M}$ Tris (Sigma) $-\mathrm{HCl}$ buffer, $\mathrm{pH} 7.5$, and $1 \mathrm{mM}$ $\mathrm{MgCl}_{2}$.

\section{Gallus}

Kidney or liver tissue samples were scissor minced and $5 \%(\mathrm{w} / \mathrm{v})$ homogenates were prepared in $0.25 \mathrm{M}$ sucrose (Mann, Density Gradient Grade) containing 0.01 $\mathrm{M}$ Hepes (Sigma) $-\mathrm{HCl}$ buffer, pH 7.5.

\section{Differential Centrifugation}

All centrifugation procedures were carried out at $4^{\circ} \mathrm{C}$ utilizing a Serval S-2 centrifuge equipped with a SS-34 rotor for the isolation of the nuclear, mitochondrial, peroxisomal, or peroxisomal-lysosomal fractions; a Spinco L-2-50 centrifuge equipped with a $\mathrm{Ti}-50$ rotor was utilized for the microsomal fractionation.

\section{Rana}

Liver: nuclear fraction, $120 \mathrm{~g} \times 10 \mathrm{~min}$ followed by three cycles of resuspension and centrifugation at $270 \mathrm{~g} \times 10 \mathrm{~min}$; mitochondrial fraction, combined supernatants from the nuclear fractionation were centrifuged at $1,475 \mathrm{~g} \times 10$ min followed by one resuspension and centrifugation at $1,475 \mathrm{~g} \times 10 \mathrm{~min}$; lysosomal-peroxisomal fraction, combined supernatants from the mitochondrial fractionation were centrifuged at $14,500 \mathrm{~g} \times 20 \mathrm{~min}$; microsomal fraction, supernatant from the lysosomal-peroxosomal fractionation was centrifuged at 165,000 $\mathrm{g} \times 30 \mathrm{~min}$; soluble fraction, the supernatant resulting from the microsomal fractionation.

Kidney: nuclear fraction, $270 \mathrm{~g} \times 10 \mathrm{~min}$ followed by three cycles of resuspension and centrifugation at $270 \mathrm{~g} \times 10 \mathrm{~min}$; mitochondrial fraction, combined supernatants from the nuclear fractionation were centrifuged at $2,445 \mathrm{~g}$ $\times 10 \mathrm{~min}$ followed by one resuspension and centrifugation at $1,935 \mathrm{~g} \times 10 \mathrm{~min}$; lysosomal-peroxisomal fraction, the combined supernatants from the mitochondrial fractionation were centrifuged at $22,500 \mathrm{~g} \times 10 \mathrm{~min}$; microsomal fraction and soluble fraction, the same as for liver. 


\section{Gallus}

Liver: nuclear fraction, $30 \mathrm{~g} \times 5 \mathrm{~min}$ followed by two cycles of resuspension and centrifugation at $30 \mathrm{~g} \times 5 \mathrm{~min}$; mitochondrial fraction, combined supernatants from the nuclear fractionation were centrifuged at $1,085 \mathrm{~g} \times 10 \mathrm{~min}$ followed by two cycles of resuspension and centrifugation of both the resuspended pellet and the supernatant derived from its sedimentation at $910 \mathrm{~g} \times 10 \mathrm{~min}$; peroxisomal fraction, the combined supernatants from the mitochondrial fractionation were centrifuged at $5,090 \mathrm{~g} \times 10 \mathrm{~min}$ followed by one resuspension and centrifugation of both the resuspended pellet and the supernatant derived from its sedimentation at $4,710 \mathrm{~g} \times 10 \mathrm{~min}$; lysosomal fraction, the combined supernatants from the peroxisomal fractionation were centrifuged at $15,200 \mathrm{~g}$ $\times 10 \mathrm{~min}$; microsomal fraction, the supernatant from the lysosomal fractionation was centrifuged at $165,000 \mathrm{~g} \times 30 \mathrm{~min}$; soluble fraction, the supernatant resulting from the microsomal fractionation.

Kidney: nuclear fraction, as for liver; mitochondrial fraction, combined supernatants from the nuclear fractionation were centrifuged at $1,475 \mathrm{~g} \times 10 \mathrm{~min}$ followed by two cycles of resuspension and centrifugation at $1,085 \mathrm{~g} \times 10 \mathrm{~min}$; peroxisomal fraction, the supernatant from the mitochondrial fractionation was centrifuged at $5,500 \mathrm{~g} \times 10 \mathrm{~min}$ followed by one resuspension and centrifugation at $5,090 \mathrm{~g} \times 10 \mathrm{~min}$; lysosomal fraction, the combined supernatants from the peroxisomal fractionation were centrifuged at $20,200 \mathrm{~g} \times 20 \mathrm{~min}$; microsomal fraction and soluble fraction, as for liver.

\section{Density Gradient Centrifugation}

Gradients were prepared and fractions collected by the procedure of Martin and Ames (1961). Linearity of gradients was confirmed either indirectly by measuring the distribution of dichlorophenol-indophenol incorporated into them or directly by determination of refractive index of individual fractions with a Bausch and Lomb refractometer. The sucrose concentration of all solutions was confirmed by the latter procedure. The density of sucrose solutions was based on sucrose concentration exclusive of the contribution of various additives (see below). All procedures were performed at $4^{\circ} \mathrm{C}$. Centrifugation was accomplished with a Spinco L-2-50 centrifuge equipped with either a SW39, SW50, or SW50.1 rotor. In all cases the total volume occupied by the gradient and the sample was $5 \mathrm{ml}$. Under these conditions $r_{\text {avg }}=7.3 \mathrm{~cm}$. The centrifuge was operated at $39,000 \mathrm{rpm}$ to yield an average g-force of $130,570 \mathrm{~g}$. All gforces referred to subsequently are based on these values. Centrifugation times refer to the time of centrifugation at maximum speed exclusive of acceleration and deceleration times.

\section{Rana}

Samples of the lysosomal-peroxisomal fraction of liver or kidney suspended in $0.25 \mathrm{M}$ sucrose (Mallinckrodt) containing $0.01 \mathrm{M}$ Tris (Sigma)-HCl buffer, $\mathrm{pH}$ 7.5 , and $1 \mathrm{mM} \mathrm{MgCl}$ were used as starting material. For kidney, gradients extended from density 1.10-1.29 and contained $0.01 \mathrm{M}$ Tris- $\mathrm{HCl}$ buffer, $\mathrm{pH} 7.5$, and $1 \mathrm{mM} \mathrm{MgCl}$ distributed uniformly throughout. For liver, gradients extended

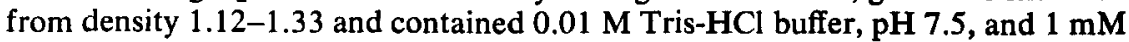
$\mathrm{MgCl}_{2}$ distributed uniformly throughout. Liver preparations were centrifuged 30 minutes. Kidney preparations were centrifuged 60 minutes. 
Gallus

Samples consisted of the mitochondrial, peroxisomal, or lysosomal fractions derived by differential centrifugation. The appropriate starting material was suspended in $0.7 \mathrm{M}$ sucrose (Mann, Density Gradient Grade) containing 0.01 M Hepes (Sigma)-HCl buffer, pH 7.5. Gradients extended from density 1.10 1.29 and contained $0.01 \mathrm{M}$ Hepes- $\mathrm{HCl}$ buffer, $\mathrm{pH} \mathrm{7.5,} \mathrm{distributed} \mathrm{uniformly}$ throughout. Centrifugation time was 60 minutes.

\section{Enzyme Assay and Protein Determination}

In all enzyme assay procedures, reaction rates were linear with enzyme concentration over the time intervals utilized; the substrate was not limiting except in the case of catalase that followed first order kinetics. Recoveries of enzymatic activity and protein in differential and gradient centrifugation analyses approached 100 percent.

Catalase: Determined by the method of Baudhuin and associates (1965) in the presence of $1.5 \mathrm{mM}$ hydrogen peroxide at $0^{\circ} \mathrm{C}$. Optical density of the peroxytitanium sulfate complex was measured at $410 \mathrm{~m} \mu$ using a Coleman $2 \mathrm{~A}$ spectrophotometer.

$\alpha$-Hydroxy acid oxidase: Determined by a modification of the method of Leighton and coworkers (1968) in the presence of $7 \mathrm{mM}$ sodium glycolate (Gallus) or $16 \mathrm{mM}$ sodium glycolate (Rana) at $37^{\circ} \mathrm{C}$. The optical density of the 2,4-dinitrophenyl hydrazone-keto-acid complex was measured at $430 \mathrm{~m} \mu$ using a Coleman $2 \mathrm{~A}$ spectrophotometer.

D-Amino acid oxidase: Determined by a modification of the method of Leighton and associates (1968) in the presence of $50 \mathrm{mM}$ D-phenylalanine (Gallus) or $100 \mathrm{mM} \mathrm{D-alanine} \mathrm{(Rana)} \mathrm{at} 37^{\circ} \mathrm{C}$. The optical density of the end product was measured as for $\alpha$-hydroxy acid oxidase.

Urate oxidase: Determined by the method of Tsukada (1968) in the presence of $21 \mu \mathrm{M}$ sodium urate at $25^{\circ} \mathrm{C}$ (Gallus) or $43 \mu \mathrm{M}$ sodium urate at $37^{\circ} \mathrm{C}$ (Rana). Decrease in optical density was measured at $293 \mathrm{~m} \mu$ using a Beckman DU spectrophotometer.

Allantoinase: Determined by the method of Brown (1964) in the presence of $12 \mathrm{mM}$ allantoin (Sigma) at $37^{\circ} \mathrm{C}$. The reaction product, allantoic acid, was determined indirectly after conversion to glyoxylic acid by controlled heating and subsequent reaction with 2,4-dinitrophenylhydrazine. The optical density of the complex thus formed was measured at $440 \mathrm{~m} \mu$ using a Coleman 2A spectrophotometer.

Xanthine dehydrogenase: Determined by a modification of the method of Croisille (1963) at $25^{\circ} \mathrm{C}$ using a reaction mixture containing $1.7 \mathrm{mM}$ Sorenson's phosphate buffer, pH 7.5; $0.45 \mathrm{mM}$ NAD (Sigma); $0.25 \mathrm{mM}$ sodium pyruvate (Sigma); $66 \mu \mathrm{M}$ flavin adenine dinucleotide (Sigma); $110 \mathrm{mgm}$ percent lactate dehydrogenase (Sigma, Type II); and $0.17 \mathrm{mM}$ xanthine (Sigma). The increase in optical density at $293 \mathrm{~m} \mu$, corresponding to the formation of uric acid, was determined using a Beckman DU spectrophotometer.

Succinic dehydrogenase: Determined by the method of Allen and coworkers (1965) at $25^{\circ} \mathrm{C}$.

Acid phosphatase: Determined by the method of Allen and Gockerman (1964) at $25^{\circ} \mathrm{C}$.

Glucose-6-phosphatase: Determined by the method of Swanson (1955) at $37^{\circ} \mathrm{C}$.

Protein: Determined by a biuret reaction as described by Bailey (1967). 

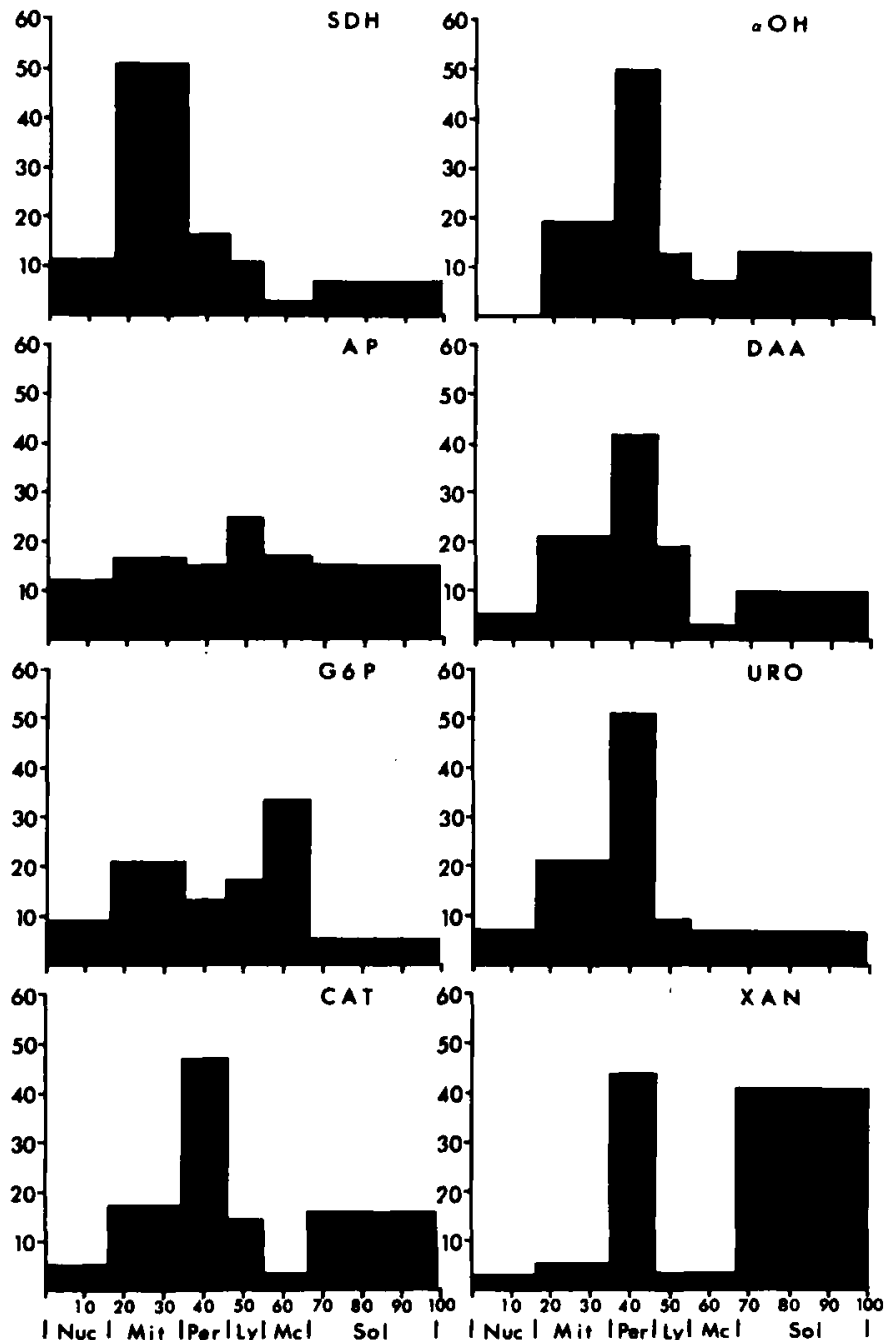

Figure 2. Differential centrifugation separation of mitochondria (Mit), peroxisomes (Per), lysosomes (Ly), and microsomes (Mc) from homogenates of chicken liver. Percentage of enzymatic activity recovered in a given fraction as compared to the whole homogenate activity is shown on the vertical axis. The distribution of total protein nitrogen expressed as a percentage of that in the whole homogenate is given on the horizontal axis. The width of each bar indicates the percentage of the total protein nitrogen recovered in that fraction. Nuc, nuclear fraction; Sol, soluble fraction; SDH, succinic dehydrogenase; AP, acid phosphatase; G6P, glucose-6-phosphatase; CAT, catalase; $\alpha \mathrm{OH}$, $\alpha$-hydroxy acid oxidase; DAA, D-amino acid oxidase; URO, urate oxidase; XAN, xanthine dehydrogenase. 


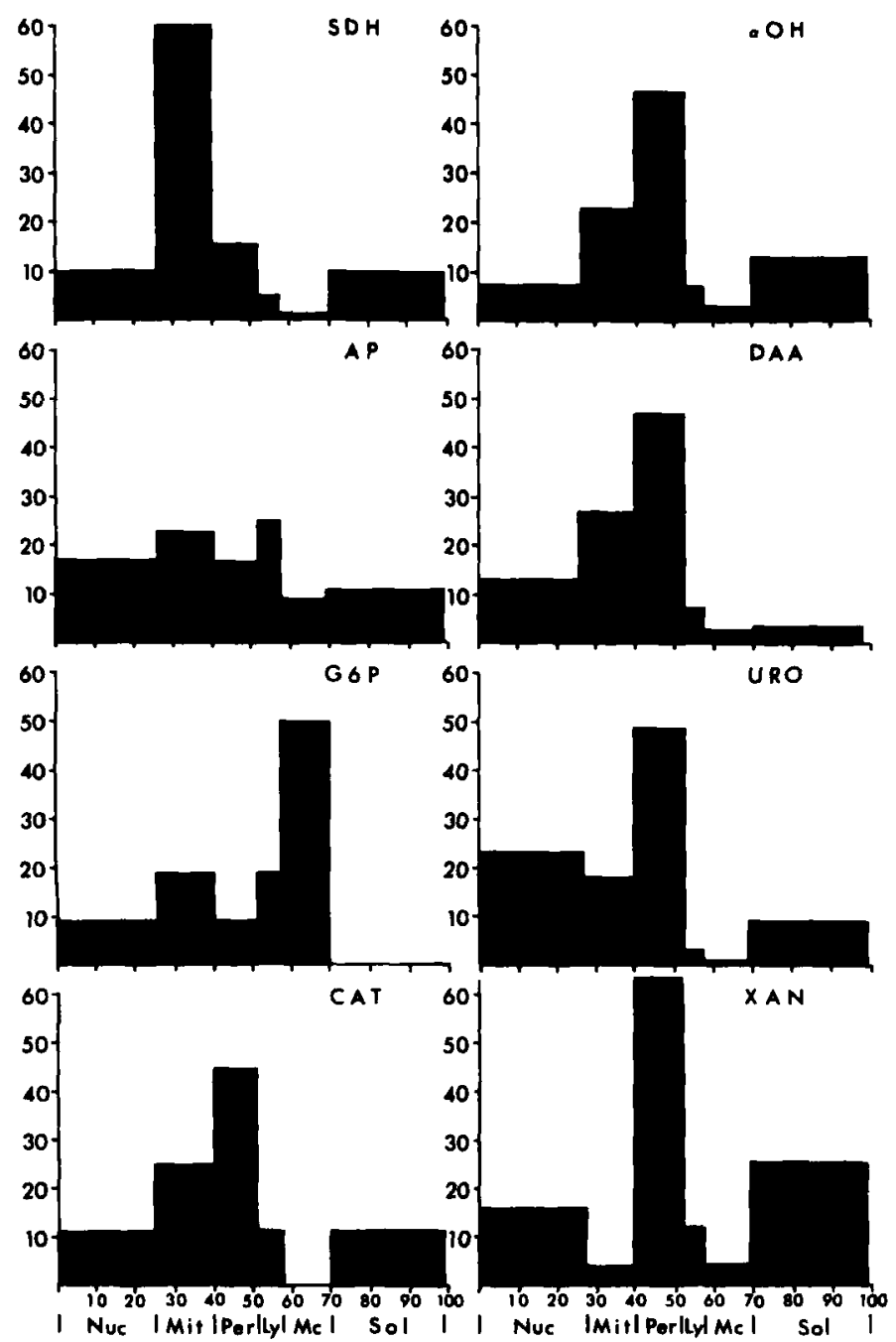

Figure 3. Differential centrifugation separation of mitochondria (Mit), peroxisomes (Per), lysosomes (Ly), and microsomes (Mc) from homogenates of chicken kidney. Percentage of enzymatic activity recovered in a given fraction as compared to the whole homogenate activity is shown on the vertical axis. The distribution of total protein nitrogen expressed as a percentage of that in the whole homogenate is given on the horizontal axis. The width of each bar indicates the percentage of the total protein nitrogen recovered in that fraction. Nuc, nuclear fraction, Sol, soluble fraction; SDH, succinic dehydrogenase; AP, acid phosphatase; G6P, glucose-6-phosphatase; CAT, catalase; $\alpha \mathrm{Oh}, \alpha$-hydroxy acid oxidase; DAA, D-amino acid oxidase; URO, urate oxidase; XAN, xanthine dehydrogenase. 


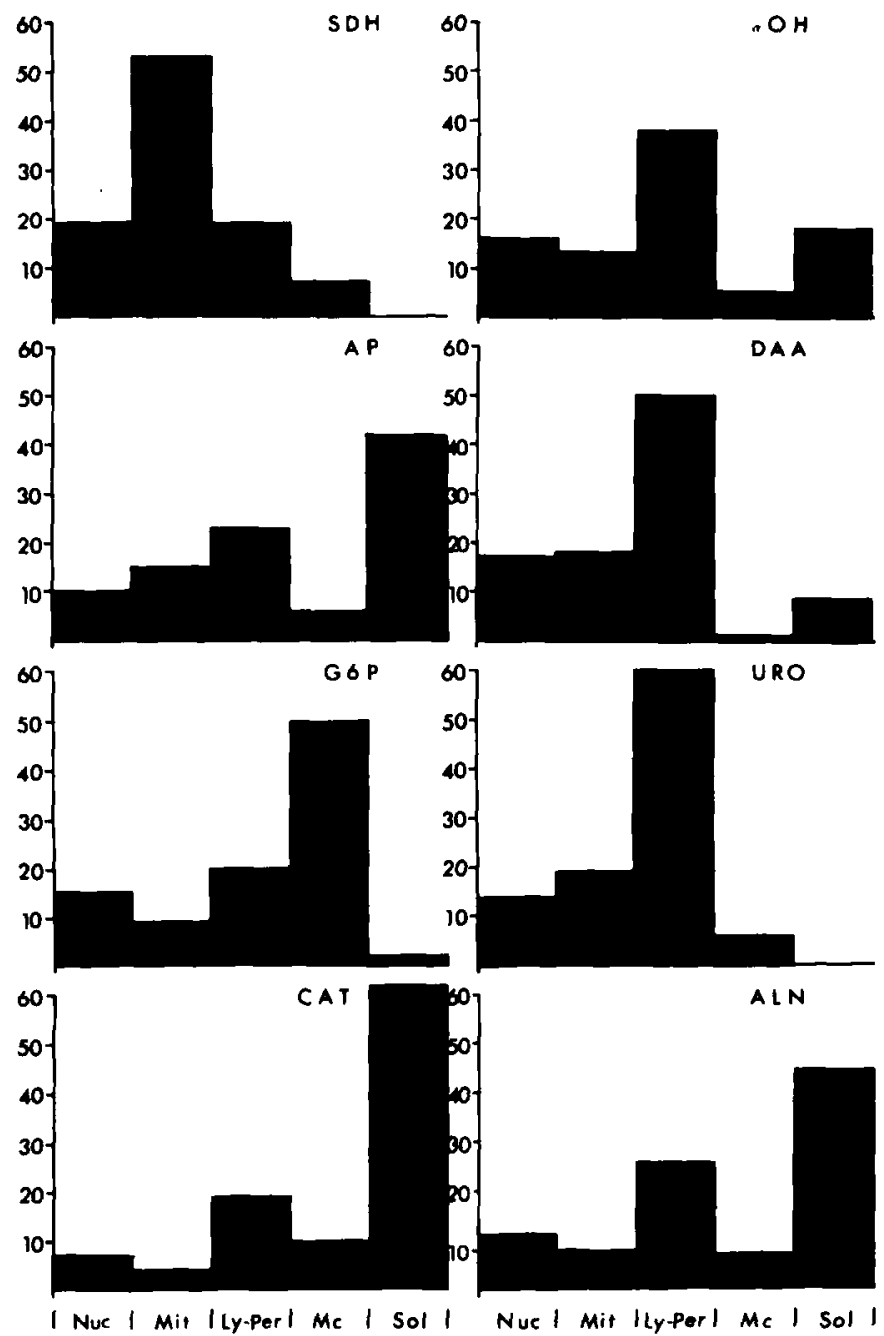

FIGURE 4. Differential centrifugation separation of mitochondria (Mit), lysosomes and peroxisomes (Ly-Per), and microsomes (Mc) from homogenates of frog liver. Percentage of enzymatic activity recovered in a given fraction as compared to the whole homogenate activity is shown on the vertical axis. The identification of the fractions is shown on the horizontal axis. Nuc, nuclear fraction; Sol, soluble fraction; SDH, succinic dehydrogenase; AP, acid phosphatase; G6P, glucose-6-phosphatase; CAT, catalase; $\alpha-\mathrm{OH}, \alpha$-hydroxy acid oxidase; DAA, D-amino acid oxidase; URO, urate oxidase; ALN, allantoinase. 

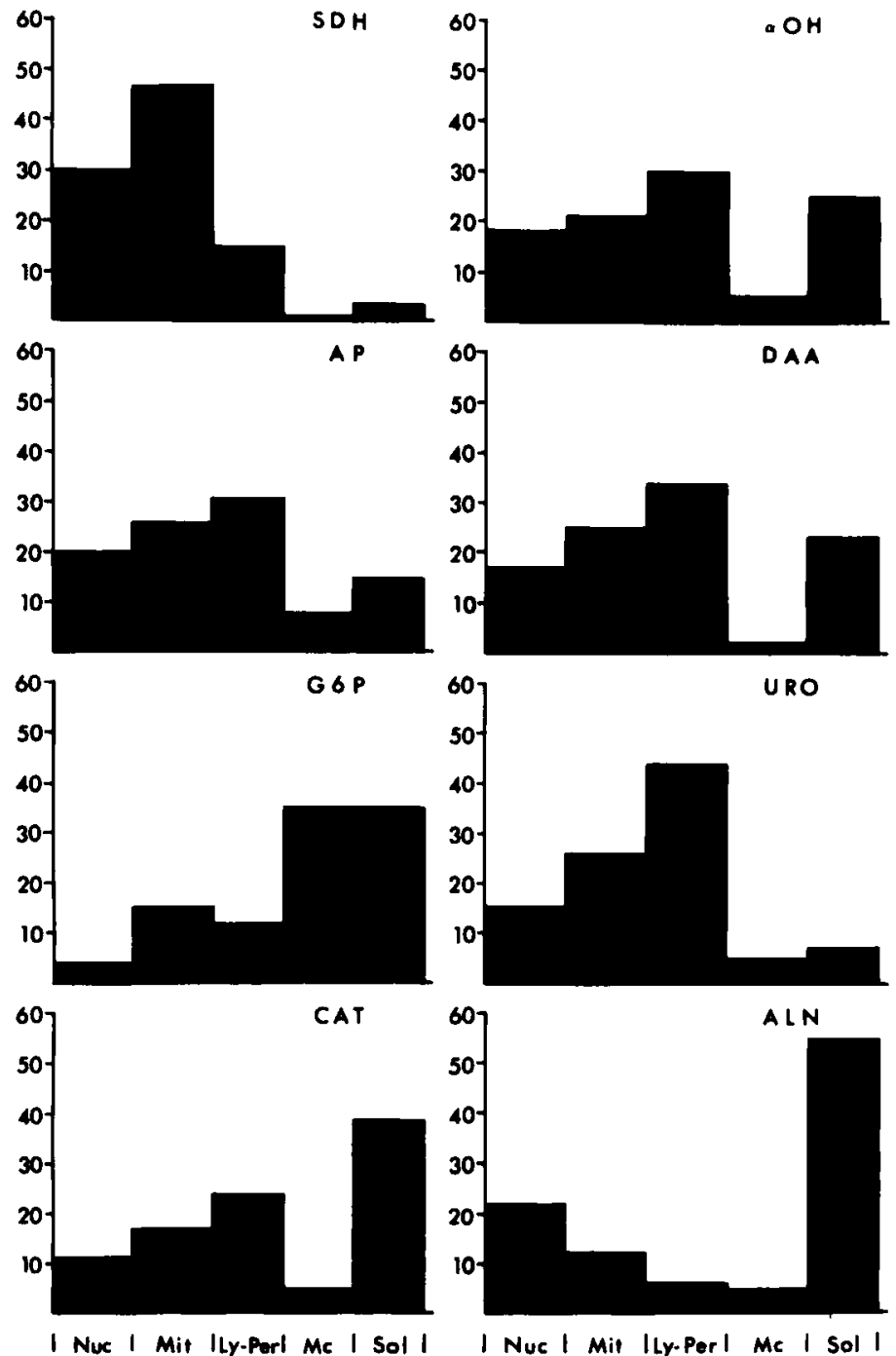

Figure 5. Differential centrifugation separation of mitochondria (Mit), lysosomes and peroxisomes (Ly-Per), and microsomes (Mc) from homogenates of frog kidney. Percentage of enzymatic activity recovered in a given fraction as compared to the whole homogenate activity is shown on the vertical axis. The identification of the fractions is shown on the horizontal axis. Nuc, nuclear fraction; Sol, soluble fraction; SDH, succinic dehydrogenase; AP, acid phosphatase; G6P, glucose-6-phosphatase; CAT, catalase; $\alpha-\mathrm{OH}, \alpha$-hydroxy acid oxidase; DAA, D-amino acid oxidase; URO, urate oxidase; ALN, allantoinase. 
Scott et al,: Enzymatic Characteristics

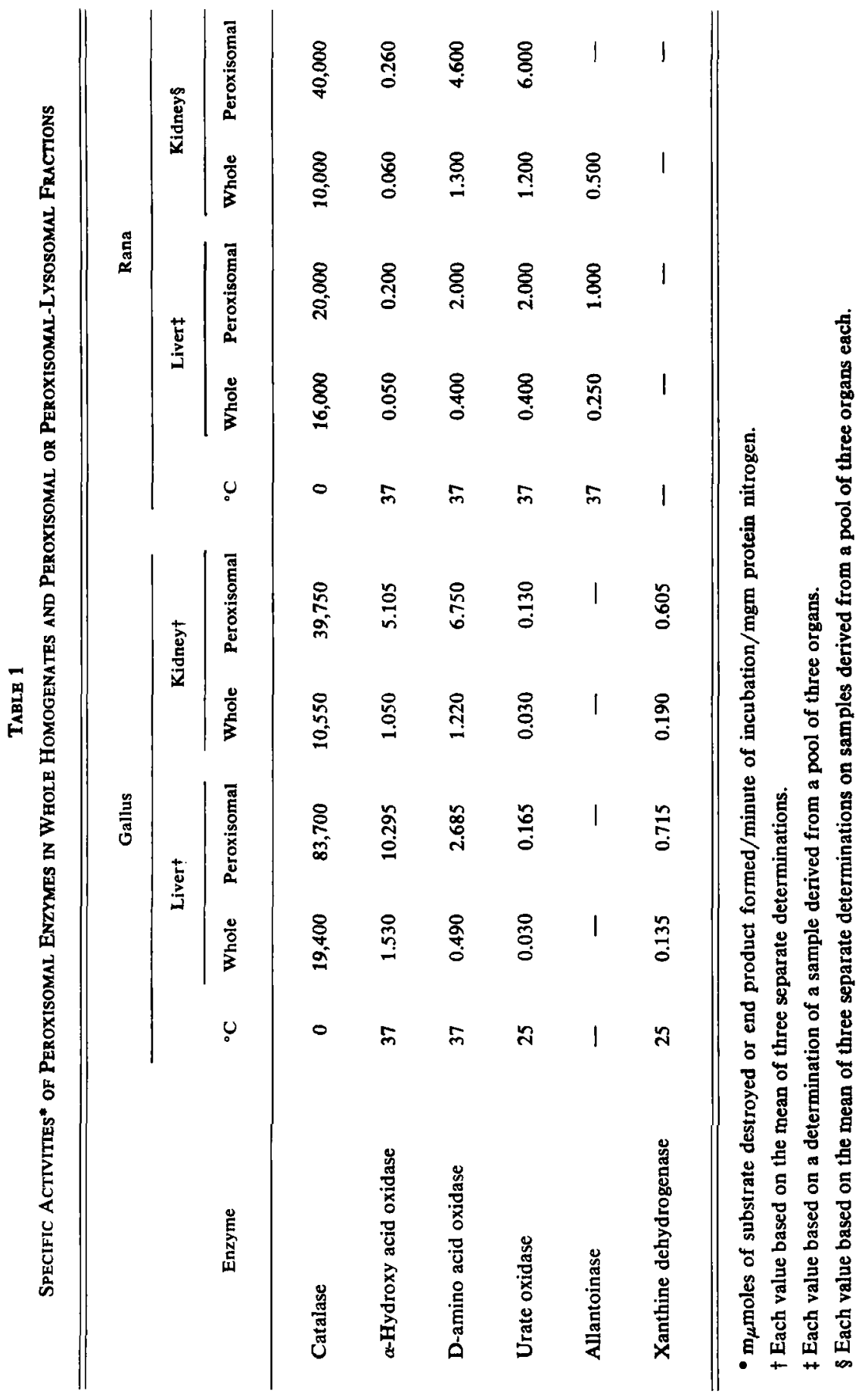




\section{RESULTS}

\section{Differential Centrifugation}

The results of differential centrifugation analyses are presented in FIGUREs 2 , 3,4 , and 5 . In these experiments the standard peroxisomal markers, catalase, $\alpha$-hydroxy acid oxidase, $\mathrm{D}$-amino acid oxidase, and urate oxidase behaved similarly and were recovered in the peroxisomal-lysosomal fraction (Rana) or in the peroxisomal fraction (Gallus) with variable proportions appearing in the soluble fraction. Xanthine dehydrogenase in birds displayed a sedimentation behavior similar to the standard peroxisomal markers and the particle-associated activity was recovered predominantly in the peroxisomal fractions of both liver and kidney. Approximately $30 \%$ of the activity of this enzyme was recovered in the soluble fractions of both liver and kidney. That portion of allantoinase in frog liver that was particle-associated likewise was recovered predominantly in the peroxisomal fraction although approximately $45 \%$ of the activity appeared in the soluble fraction. No enrichment of allantoinase activity in any particulate fraction of frog kidney could be achieved and $55 \%$ of the activity appeared in the soluble fraction.

The sedimentation of mitochondrial and microsomal material, as evidenced by the distribution of succinic dehydrogenase and glucose-6-phosphatase, respectively, was distinct from that of the standard peroxisomal markers and xanthine dehydrogenase and allantoinase. Lysosomes, determined by their content of acid phosphatase, could not be conveniently separated from peroxisomes of frog liver and kidney. However, in chicken liver and kidney it was routinely possible to separate a peroxisomal fraction in which the proportion of acid phosphatase activity was relatively low.

Calculation of specific activity values based on whole homogenates and peroxisomal or peroxisomal-lysosomal fractions (TABLE 1) for catalase, $\alpha$-hydroxy acid oxidase, D-amino acid oxidase, urate oxidase, allantoinase, and xanthine dehydrogenase showed, with two exceptions, at least a four-fold enrichment of activity in the fraction as compared to the whole homogenate value. The exceptions were allantoinase in frog kidney lysosomal-peroxisomal fractions and catalase in frog liver lysosomal-peroxisomal fractions. These latter results reflect the preponderantly large proportion of the enzyme found in the soluble fraction in these cases.

\section{Gradient Centrifugation}

The results of gradient centrifugation analysis are presented in FIGURES 6, 7, 8, and 9. Average median particle densities derived from these sedimentation analyses are give in TABLE 2 . The sedimentation behavior of particle-associated catalase, $\alpha$-hydroxy acid oxidase, D-amino acid oxidase, urate oxidase, allantoinase, and xanthine dehydrogenase derived from each tissue within a species was similar. This behavior was in contrast to that displayed by lysosomes or mitochondria, as reflected by the sedimentation of particle-associated acid phosphatase or succinic dehydrogenase. Analysis of varience of ranks by the Kruskal-Wallis method (Campbell, 1967) indicated, within a given population of particles containing catalase, $\alpha$-hydroxy acid oxidase, $D$-amino acid oxidase, urate oxidase, allantoinase or xanthine dehydrogenase, no significant difference ( $P>0.05$ ) between the median particle densities. Analysis by the Mann-Whitney U-test (Campbell, 1967) indicated that the median densities of mitochondria and lysosomes as reflected by the sedimentation of succinic dehydrogenase and 
TABLE 2

Average Median Densities of Lysosomes, Mitochondria, and Peroxisomes From AMPHIBIAN aND AVIan KidNEy AND Liver

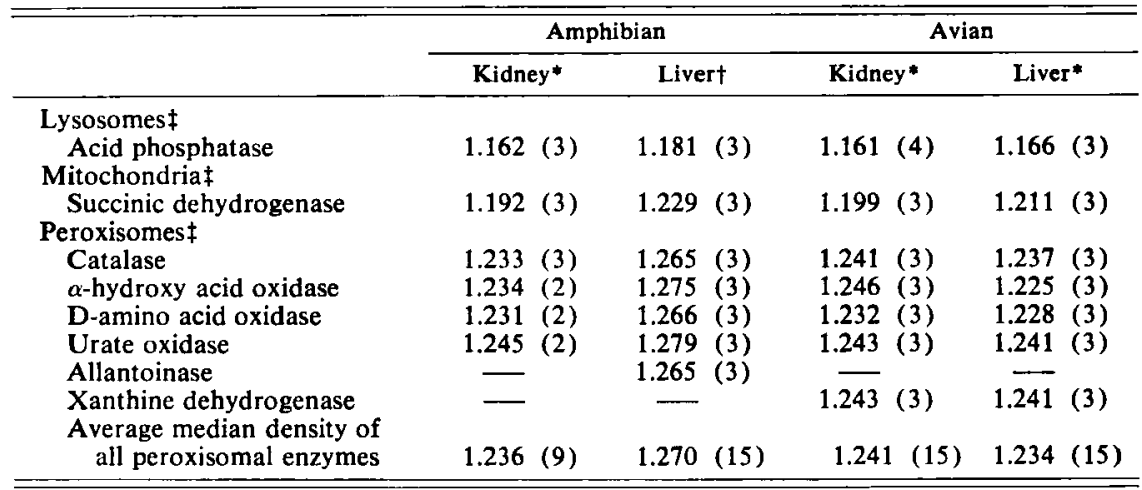

* Centrifugal field, $130,580 \mathrm{~g} \times 60 \mathrm{~min}$ exclusive of acceleration and deceleration times.

$\dagger$ Centrifugal field, $130,580 \mathrm{~g} \times 30 \mathrm{~min}$ exclusive of acceleration and deceleration times.

$\ddagger$ Average median density followed by number of determinations in parentheses.

acid phosphatase were significantly different $(P<0.05)$ from those of the above mentioned particle-associated enzymes.

The times of centrifugation and hence the total g-forces employed in these studies were less than those commonly utilized for the determination of median equilibrium particle densities (Beaufay et al., 1959). In a series of analyses carried out with the mitochondrial, peroxisomal, and lysosomal fractions of chicken liver it was found that centrifugation for 30 minutes at $130,570 \mathrm{~g}$ yielded average median particle densities at least $98 \%$ of the median particle densities, as based on 120 minutes of centrifugation under the same g-force when catalase and succinic dehydrogenase were used as reference enzymes. Particle-associated acid phosphatase showed, under these conditions, an average particle density of $91 \%$ of that achieved at 120 minutes of centrifugation. When centrifugation times were increased to 60 minutes using the same g-force, all particle-associated catalase, succinic dehydrogenase, and acid phosphatase achieved more than $99 \%$ of the density, as based on 120 minutes of centrifugation. The advantages gained through shorter centrifugation times (sharper sedimentation boundaries, reduced enzyme denaturation, reduced enzyme dislocation, and absence of "pelleting") more than compensated for the possible slight underestimation of median particle densities.

\section{Electron Microscopy}

Electron micrographs of peroxisomes present in liver and kidney tissues of Rana pipiens and Gallus gallus are shown in FIGURE 10. In all cases the peroxisomes were surrounded by a single membrane, contained a dense granular matrix, and, in the case of chicken kidney and frog liver and kidney, routinely displayed core structures. Core structures were difficult to observe with consistency in the peroxisomes of chicken liver. However, in several instances (FIGURE 10, C) cores were observed in the peroxisomes of this tissue. The difference in density between these cores and the peroxisomal matrix was slight and complicated their identification. 

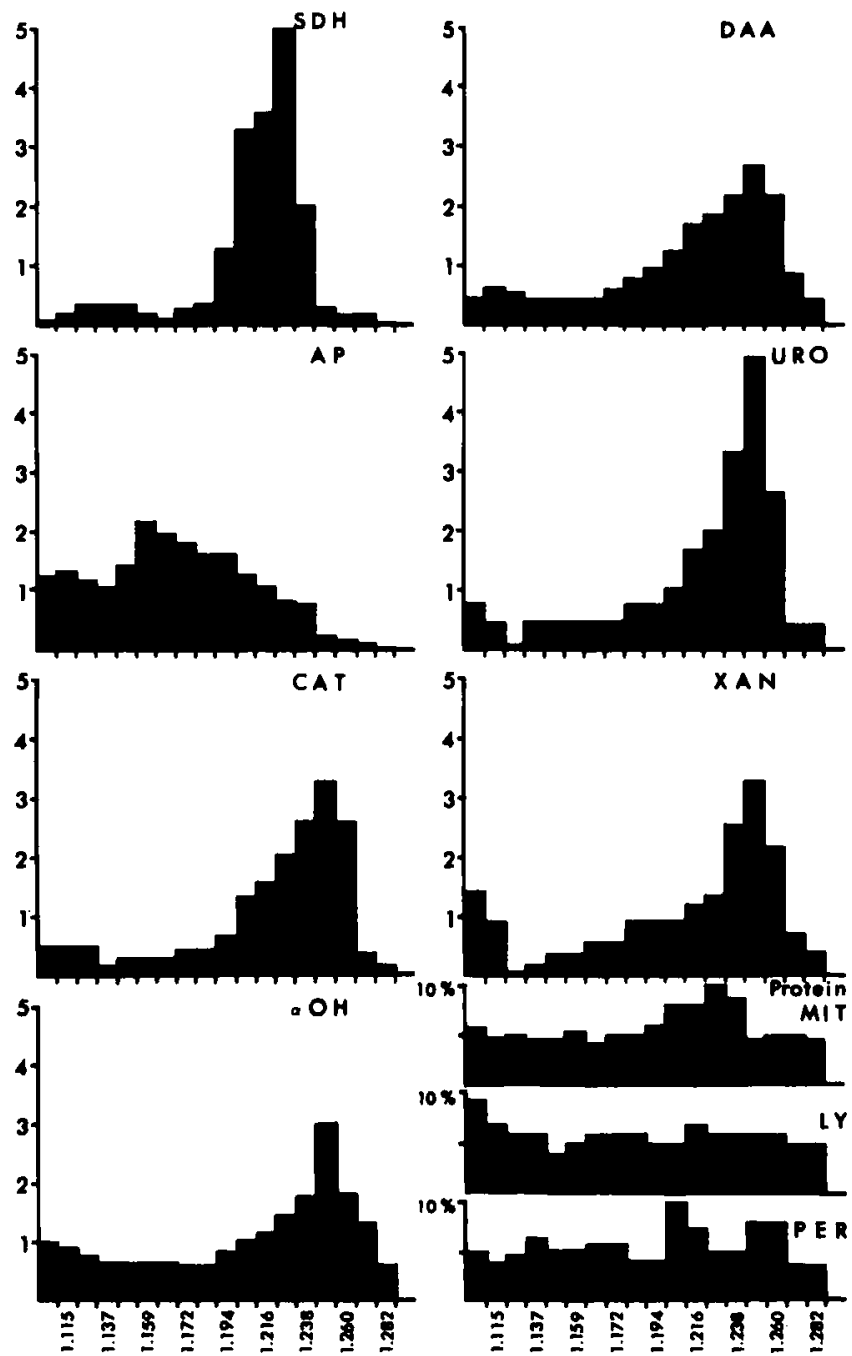

Figure 6. Density gradient separation of mitochondria, lysosomes, and peroxisomes derived from chicken liver. Relative activity calculated as the enzyme activity in each fraction divided by the mean recovered enzyme activity per fraction is shown on the vertical axis. Mean fraction density based on sucrose concentration is shown on the horizontal axis. The distribution of total protein nitrogen in the various gradients (lower right) is expressed as the percent of total protein nitrogen in a given fraction computed from the content of total protein nitrogen of the starting material. The first bar (farthest left) in each histogram represents sample material and soluble enzyme which did not enter the gradient. SDH, succinic dehydrogenase; AP, acid phosphatase; CAT, catalase; $\alpha O H$, $\alpha$-hydroxy acid oxidase; DAA, D-amino acid oxidase; URO, urate oxidase; XAN, xanthine dehydrogenase; MIT, mitochondria; LY, lysosomes; PER, peroxisomes. 

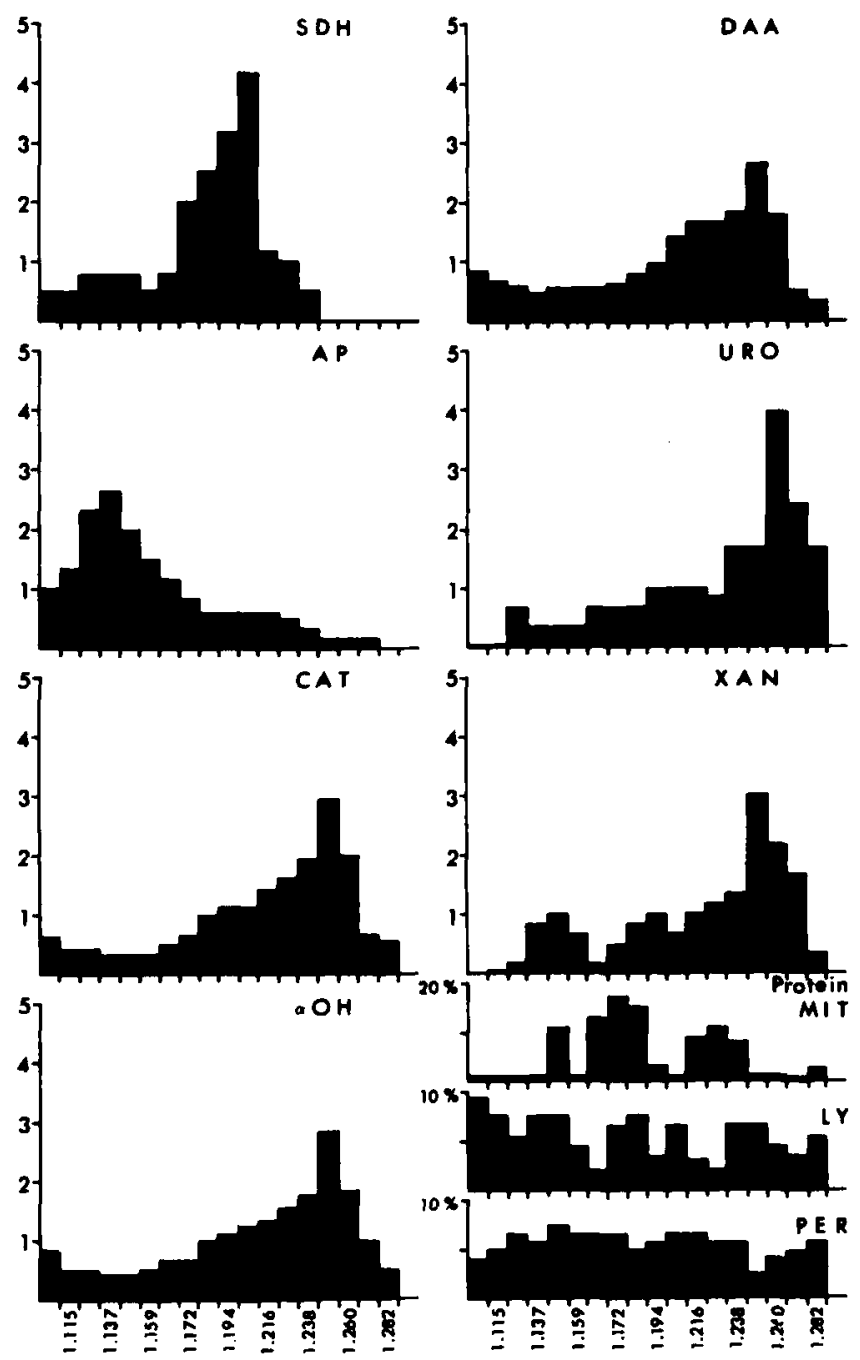

Figure 7. Density gradient separation of mitochondria, lysosomes, and peroxisomes derived from chicken kidney. Relative activity calculated as the enzyme activity in each fraction divided by the mean recovered enzyme activity per fraction is shown on the vertical axis. Mean fraction density based on sucrose concentration is shown on the horizontal axis. The distribution of total protein nitrogen in the various gradients (lower right) is expressed as the percent of total protein nitrogen in a given fraction computed from the content of total protein nitrogen of the starting material. The first bar (farthest left) in each histogram represents sample material and soluble enzyme that did not enter the gradient. SDH, succinic dehydrogenase; AP, acid phosphatase; CAT, catalase; $\alpha \mathrm{OH}, \alpha$-hydroxy acid oxidase; DAA, D-amino acid oxidase; URO, urate oxidase; XAN, xanthine dehydrogenase; MIT, mitochondria; LY, lysosomes; PER, peroxisomes. 

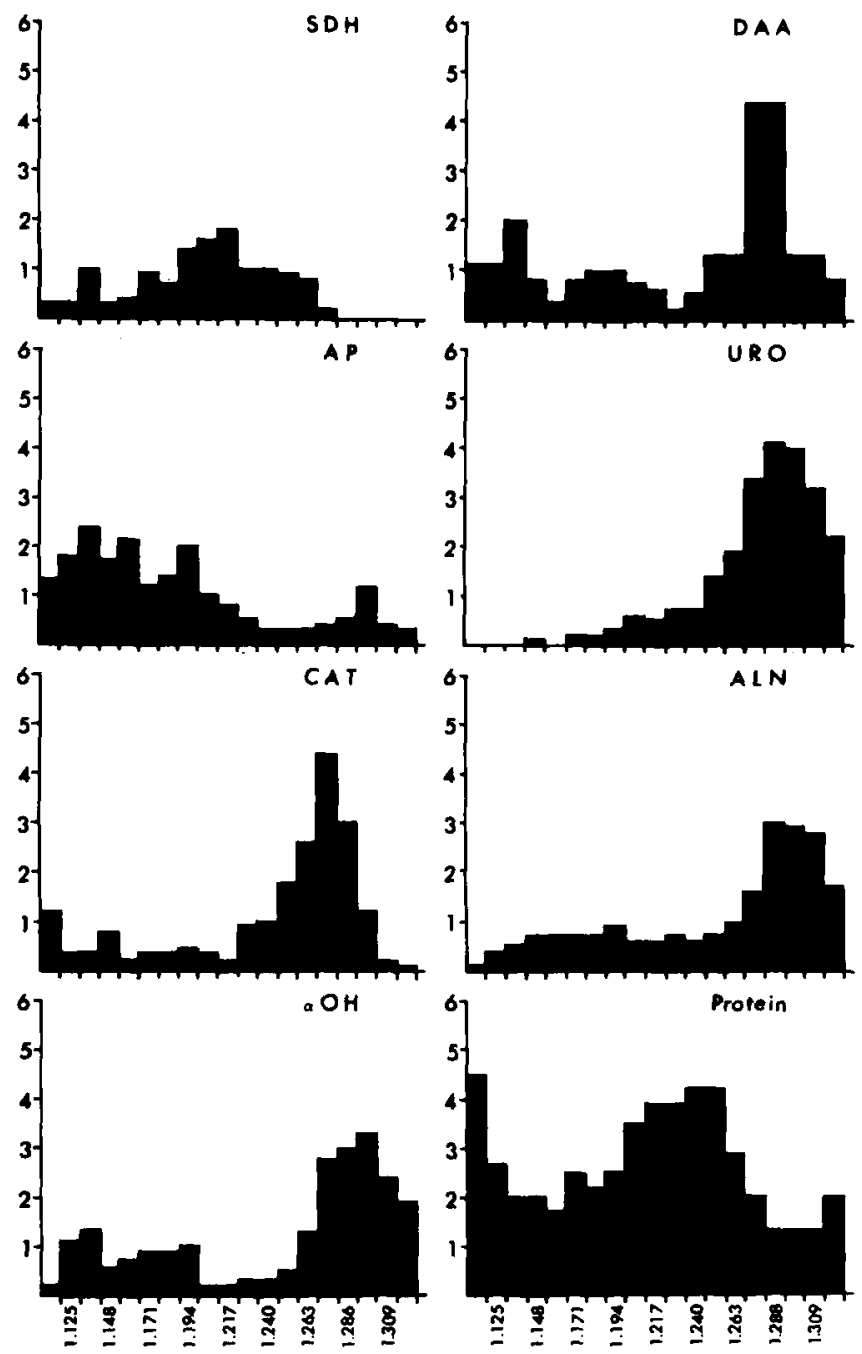

Figure 8. Density gradient separation of lysosomal-peroxisomal material derived from frog liver. Relative specific activity calculated as the ratio of percent enzyme activity per fraction to percent total protein nitrogen per fraction is shown on the vertical axis. Mean fraction density based on sucrose concentration is shown on the horizontal axis. The distribution of total protein nitrogen (lower right) in the gradient is expressed as the percent of total protein nitrogen in a given fraction computed from the content of total protein nitrogen of the starting material. The first bar (farthest left) in each histogram represents sample material and soluble enzyme that did not enter the gradient. SDH, succinic dehydrogenase; AP, acid phosphatase; CAT, catalase; $\alpha \mathrm{OH}, \alpha$-hydroxy acid oxidase; DAA, D-amino acid oxidase; URO, urate oxidase; ALN, allantoinase. 


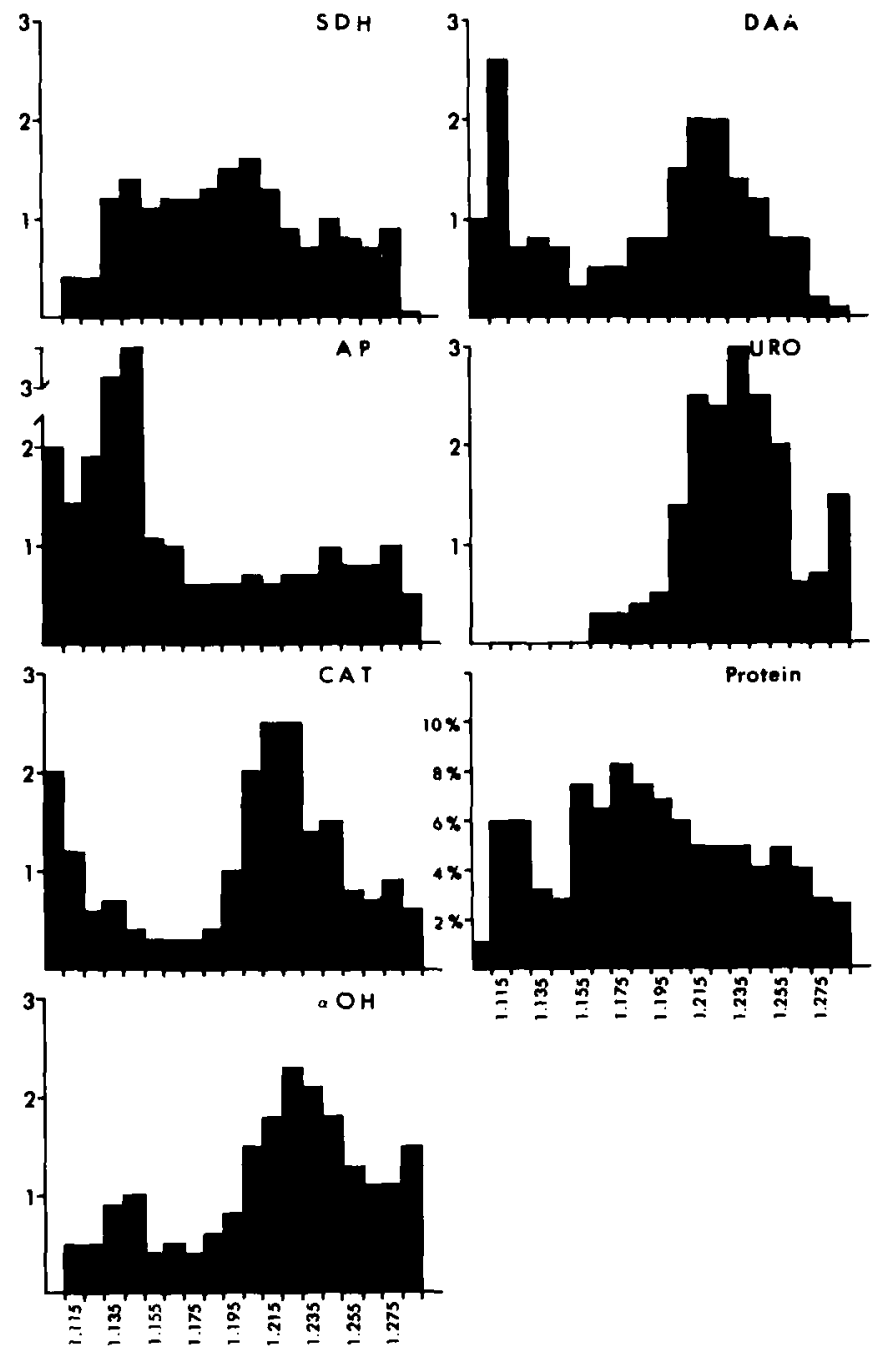

FIGURE 9. Density gradient separation of lysosomal-peroxisomal material derived from frog kidney. Relative specific activity calculated as the ratio of percent enzyme activity per fraction to percent total protein nitrogen per fraction is shown on the vertical axis. Mean fraction density based on sucrose concentration is shown on the horizontal axis. The distribution of total protein nitrogen (lower right) in the gradient is expressed as the percent of total protein nitrogen in a given fraction computed from the content of total protein nitrogen of the starting material. The first bar (farthest left) in each histogram represents sample material and soluble enzyme that did not enter the gradient. SDH, succinic dehydrogenase; AP, acid phosphatase; CAT, catalase; $\alpha \mathrm{OH}, \alpha$-hydroxy acid oxidase; DAA, D-amino acid oxidase; URO, urate oxidase. 


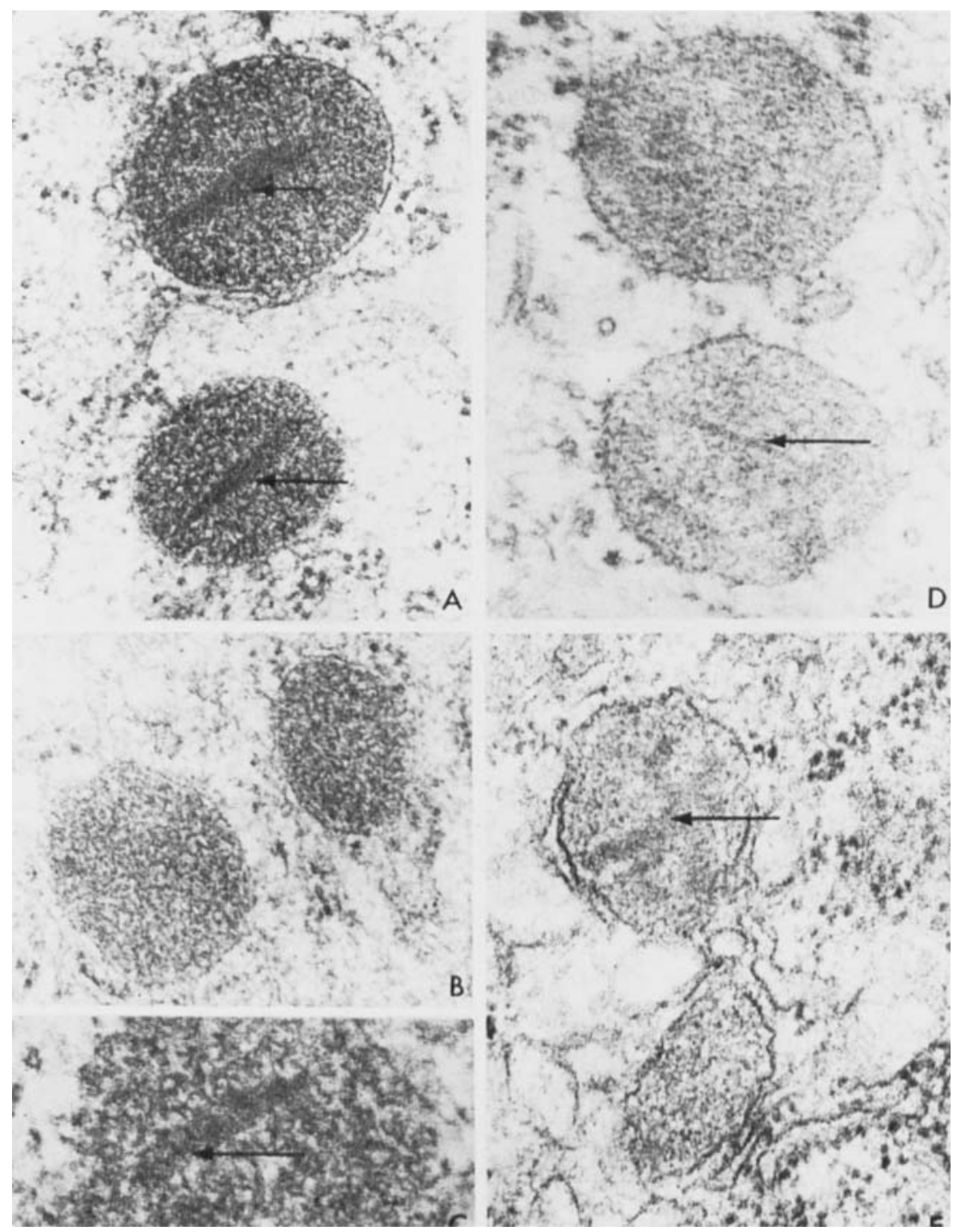

Figure 10. Electron micrographs of peroxisomes in chicken and frog liver and kidney. Tissues fixed in glutaraldehyde and postfixed in osmium, followed by staining with uranyl acetate and lead citrate. A. Chicken kidney $(\times 88,000)$, core structures are indicated by arrows. B. Chicken liver $(X 100,000)$, core structures are not visible in these particles that are interpreted as peroxisomes on the basis of the dense granular matrix. $C$. Chicken liver $(X 170,000)$, core structure (arrow) is difficult to discern due to slight difference in density between it and the surrounding matrix. D. Frog kidney $(\times 140,000)$, elongate core structure is visible (arrow) in peroxisome in lower portion of photograph. E. Frog liver $(\times 105,000)$, swastika-shaped core in peroxisome is indicated by the arrow. This peroxisome is enveloped by membranes of the endoplasmic reticulum. 


\section{Discussion}

The data presented above establishes the presence of peroxisomes in the liver and kidney tissue of birds and amphibians. Morphologically the particles in amphibian liver and kidney and in avian liver and kidney resemble those described in other species and contain the identifying core structure (Hruban \& Rechcigl, 1969). Biochemically the peroxisomes of amphibian and avian liver and kidney resemble those of other vertebrate orders thus far examined and contain catalase, $\alpha$-hydroxy acid oxidase, D-amino acid oxidase, and urate oxidase (deDuve \& Baudhuin, 1966). Like peroxisomes from other sources (Muller et al., 1968), those identified in this study are typified by high equilibrium densities relative to those of mitochondria and lysosomes. The parallel sedimentation behavior of xanthine dehydrogenase in avian liver and kidney and of allantoinase in amphibian liver as compared to that of the standard peroxisomal markers indicates that these should now be regarded as peroxisomal constituents.

The association of xanthine dehydrogenase, urate oxidase, and allantoinase with peroxisomes of amphibians and birds provides strong circumstantial evidence that these particles play a role in purine catabolism at least in certain species (FIGURE 1). The presence of urate oxidase in mammalian liver peroxisomes (deDuve \& Baudhuin, 1968; Leighton et al., 1968) and in the peroxisomes of Acanthoamoeba (Müller \& Møller, 1967) is supportive of this premise. The recent observations of Ory and coworkers (1969) associating allantoinase with a peroxisome-like particle in germinating castor beans coupled with those cited above suggest that a role of the peroxisome in purine catabolism may have broad phylogenetic distribution.

If our contention that the enzymes of purine catabolism are associated with peroxisomes is correct, it would be expected that all constituents of the degradative system would reside in them, of course, with the proviso that certain elements have been lost during the evolution of particular groups (FIGURE 1 ). This expectation is borne out in the case of the peroxisomes of Gallus. Xanthine dehydrogenase and low levels of urate oxidase were present in the particles. The previous reports of the absence of urate oxidase in the bird (Baldwin, 1964) can probably be accounted for on the basis of less sensitive assay procedures. In the case of Rana, however, allantoinase was not associated with the peroxisomes of kidney but appeared predominantly in the soluble phase although it was associated with the peroxisomes of liver. Allantoinase, as will be reported fully elsewhere, even though present in frog liver and kidney, was not particle associated and appeared almost exclusively in the soluble phase. The reasons for these discrepancies are not clear. The linkage of various enzymes with the peroxisome varies widely. Urate oxidase appears universally to be bound firmly to structure within the particle (deDuve \& Baudhuin, 1966). Other peroxisomal constituents, however, differ in the nature of their association with the particle (Beard \& Allen, 1968) and in terms of the conditions under which they are released into the supernatant phase. Indeed, the apparent ease with which certain peroxisomal enzymes are released into the supernatant differs between different tissues within a given animal. In this study greater amounts of catalase, an apparent universal peroxisomal marker enzyme (Muller et al., 1968), were present in the supernatant phase of frog liver homogenates than in that of frog kidney homogenates. Given these circumstances, it is possible that our failure to observe localization of allantoinase in frog kidney peroxisomes or allantoicase in frog liver and kidney peroxisomes may have been due to improper technical pro- 
cedures. The inclusion of magnesium ion in the suspending medium was necessary to conserve the peroxisumal content of allantoinase in frog liver.

It is now established that peroxisomes in certain plant cells contain the components of the glyoxylate cycle (Breidenbach et al., 1968). Elements of this cycle are present in Tetrahymena pyriformis (Müller et al., 1968). Glyoxylate in these situations is a key intermediate. In photorespiring plants, glycolate oxidation is responsible for the increased respiratory rate. Glycolate oxidase and NADH-glyoxylate reductase are present in the peroxisomes of these plants (Tolbert et al., 1968a; Tolbert et al., 1968b). Glyoxylate is also a central intermediate in the postulated purine cycle (Brown et al., 1966). Glycolate oxidase and $\alpha$-hydroxy acid oxidase have a broad phylogenetic distribution in the peroxisomes thus far examined (Müller et al., 1968). Either enzyme appears capable of the production of glyoxylate from glycolate. Thus glyoxylate and some of the enzymes involved in its conversion are linked with the function of three metabolic sequences that appear to be present in peroxisomes. It is possible that this coincidence may be related to the evolution of these contemporary pathways (the glyoxylate cycle, photorespiration, and purine catabolism or the purine cycle) from a common ancestral system. The nature of the ancestral system is unknown. DeDuve and Baudhuin (1966) have suggested that it may be the glyoxylate cycle itself. If our contentions are correct, an elaboration of a portion of the primitive system in higher forms may reside in the enzymes of purine metabolism.

\section{SUMMARY}

Peroxisomes have been identified in liver and kidney tissues of Gallus gallus and Rana pipiens by electron microscopy and by differential and sucrose density gradient centrifugation. Morphologically, the peroxisomes of these tissues are bounded by a single dense membrane, contain a granular matrix, and possess a core structure. When subjected to differential centrifugation and to density gradient centrifugation the peroxisomes of these tissues were identified by their content of catalase, $\alpha$-hydroxy acid oxidase, D-amino acid oxidase, and urate oxidase. These identifying enzymes sedimented as a group and occupied significantly more dense regions of the gradients than did mitochondria or lysosomes as identified by their content of succinic dehydrogenase or acid phosphatase, respectively. Allantoinase from frog liver and xanthine dehydrogenase from chicken liver and kidney showed sedimentation properties identical to those of the standard peroxisomal marker enzymes. When the median densities occupied by particles containing allantoinase or xanthine dehydrogenase were compared to those of particles containing catalase, $\alpha$-hydroxy acid oxidase, D-amino acid oxidase, and urate oxidase no significant difference was found. On the basis of the association of urate oxidase, xanthine dehydrogenase, and allantoinase with the peroxisomes from liver and kidney of chickens or frogs, it is concluded that this particle may play a role in the degradation of purines.

\section{ACKNOWLEDGMENT}

The authors wish to thank Dr. Dusan Baic, Department of Zoology, The University of Michigan for preparations of the electron micrographs. 


\section{REFERENCES}

Allen, J., M. Beard \& S. Kleinbergs. 1965. The localization of $\alpha$-hydroxy acid oxidase in renal microbodies. J. Exp. Zool. 160: 329-344.

Allen, J. \& J. Gockerman. 1964. Electrophoretic separation of multiple forms of particleassociated acid phosphatase. Ann. N. Y. Acad. Sci. 121: 615-633.

Balley, J. 1967. Techniques in Protein Chemistry. : 341. Elsevier Company. New York.

Baldwin, E. 1964. An Introduction to Comparative Biochemistry. : 1-179. Cambridge University Press. New York.

Baudhuin, P., H. Beaufay \& C. deDuve. 1965a. Combined biochemical and morphological study of particulate fractions from rat-liver. Analysis of preparations enriched in lysosomes or in particles containing urate oxidase, D-amino acid oxidase, and catalase. J. Cell Biol. 26: 219-243.

Baudhuin, P., M. Müllef, B. Poole \& C. DeDuve. 1965b. Nonmitochondrial oxidizing particles (microbodies) in rat liver and kidney and in Tetrahymena pyriformis. Biochem. Biophys. Res. Commun. 20: 53-59.

Beard, M. \& J. Allen. 1968. A study of properties of renal microbodies of the rat. J. Exp. Zool. 168: 477-489.

Beaufay, H., D. Bendall, P. Baudhuin, R. Wattiaux \& C. DeDuve. 1959. Tissue fractionation studies. 13. Analysis of mitochondrial fractions from rat liver by densitygradient centrifugation. Biochem. J. 73: 628-637.

Breidenbach, R., A. KaHN \& H. Beevers. 1968. Characterization of glyoxysomes from castor bean endosperm. Plant Physiol. 43: 705-713.

Brown, G. 1964. Allantoinase assay procedure. Amer. Zool. 4: 310.

Brown, G., J. James, R. Henderson, W. Thomas, R. Robinson, A. Thompson, E. Brown \& S. Brown. 1966. Uricolytic enzymes in liver of the dipnoan Protopterus aethiopicus. Science 153: 1653-1654.

Camprell, R. 1967. Statistics for Biologists. : 1-242. Cambridge University Press. New York.

Crolsille, V. 1963. Developmental, kinetic, and immunological studies of enzymes. Ann. Rept. Director Dept. Embryol. Carnegie Inst. Wash., Year Book. 62: 428-437.

DeDuve, C. \& P. Baudhuin. 1966. Peroxisomes (microbodies and related particles). Physiol. Revs. 46: 323-357.

Hruban, Z. \& M. Rechcigl. 1969. Microbodies and related particles. Suppl. 1, Int. Rev. Cytol. : 1-296. Academic Press. New York.

Leighton, F., B. Poole, H. Beaufay, P. Baudhuin, J. Coffey, S. Fowler \& C. deDuve. 1968. The large-scale separation of peroxisomes, mitochondria, and lysosomes from the livers of rats injected with Triton WR-1339. J. Cell Biol. 37: 482-513.

MARTIN, R. \& B. AMES. 1961. A method for determining the sedimentation behavior of enzymes: Application to protein mixtures. J. Biol. Chem. 236: 1372-1379.

Müller, M., J. HoGg \& C. DEDUve. 1968. Distribution of tricarboxylic acid cycle enzymes and glyoxylate cycle enzymes between mitochondria and peroxisomes in Tetrahymena pyriformis. J. Biol. Chem. 243: 5358-5395.

Müller, M. \& M. Møller. 1967. Peroxisomes in Acanthamoeba. J. Protozool. 14 (Suppl.): 11.

ORY, R., C. GoRdon \& R. SINGH. 1969. Ureide metabolism in castor beans, evidence of a particle-bound allantoinase. Phytochemistry 8 : 401-404.

Swanson, M. 1955. Glucose-6-phosphatase from liver. In Methods in Enzymology. S. Colwick and N. Kaplan, Eds. 2: 541. Academic Press. New York.

Tolbert, N., A. Oeser, T. Kisaki, R. Hageman \& R. Yamazaki. 1968a. Peroxisomes from spinach leaves containing enzymes related to glycolate metabolism. J. Biol. Chem. 243: 5179-5184.

Tolbert, N., A. Oeser, R. Yamazaki, R. Hageman \& T. Kisaki. 1968b. A survey of plants for leaf peroxisomes. Plant Physiol. 44; 135-147.

Tsukada, H., Y. Mochizuki \& T. Konishi. 1968. Morphogenesis and development of microbodies of hepatocytes of rats during pre- and postnatal growth. J. Cell Biol. 37: 231-243.

Visentin, L. \& J. Allen. 1969. Allantoinase: Association with amphibian hepatic peroxisomes. Science $163: 1463-1464$.

\section{Discussion of the Paper}

Dr. H. BeEvers (Purdue University, Lafayette, Ind.): Dr. Timer in my laboratory has looked at the distribution of these enzymes (of purine metabolism) 
in castor bean endosperm. Allantoinase is present not only in the glyoxysome (peroxisome) band but also in some higher bands in the gradient. In contrast to this, urate oxidase is specifically confined to the glyoxysome. In view of your comments about the central role of glyoxylate in all of these different organelles, I thought you were going to decide that the best name for them was glyoxysome (not purinosome).

DR. Allen: One comment concerning Dr. Beever's statement-a recent paper has appeared in which allantoicase was examined in peanut seedlings. There, as in the frog, it was insoluble. Have you looked at that?

Dr. Beevers: We have no very definite enzyme assay for allantoicase now.

Mr. Gross (National Institutes of Health, Bethesda, Md.) Why is there Damino acid oxidase in the peroxisome or, for that matter, what is the naturally occurring substrate for it?

DR. DEDUVE: There are indications that the natural substrate may be D-amino acids coming from the bacterial cell wall. As you know, these may be absorbed from the intestine. There is practically no D-amino acid oxidase in germ-free rats but, if dead bacteria are fed, the enzyme appears or increases in the kidney. This suggests, first of all, that this enzyme, like many of the peroxisomal enzymes, is inducible, and secondly, that the D-amino acids from the bacteria do indeed enter the circulation. 